Article

\title{
Coordination Control Strategy for AC/DC Hybrid Microgrids in Stand-Alone Mode
}

\author{
Dwi Riana Aryani and Hwachang Song *
}

Department of Electrical and Information Engineering, Seoul National University of Science and Technology, Seoul 01811, Korea; dwiriana@seoultech.ac.kr

* Correspondence: hcsong@seoultech.ac.kr; Tel.: +82-2-970-6403

Academic Editor: Jang-Ho Lee

Received: 31 December 2015; Accepted: 7 June 2016; Published: 18 June 2016

\begin{abstract}
Interest in DC microgrids is rapidly increasing along with the improvement of DC power technology because of its advantages. To support the integration process of DC microgrids with the existing AC utility grids, the form of hybrid AC/DC microgrids is considered for higher power conversion efficiency, lower component cost and better power quality. In the system, AC and DC portions are connected through interlink bidirectional AC/DC converters (IC) with a proper control system and power management. In the stand-alone operation mode of AC/DC hybrid microgrids, the control of power injection through the IC is crucial in order to maintain the system security. This paper mainly deals with a coordination control strategy of IC and a battery energy storage system (BESS) converter under stand-alone operation. A coordinated control strategy for the IC, which considers the state of charge (SOC) level of BESS and the load shedding scheme as the last resort, is proposed to obtain better power sharing between $A C$ and DC subgrids. The scheme will be tested with a hybrid AC/DC microgrid, using the tool of the PSCAD/EMTDC software.
\end{abstract}

Keywords: battery energy storage system; droop control; hybrid AC/DC microgrid; interlink bidirectional AC/DC converter; power management

\section{Introduction}

The increasing penetration of dispersed energy resources (DERs) in distribution systems has improved microgrids' implementation. The concept of the microgrid [1,2] includes the operation and control scheme, voltage and power regulation and energy management. At the beginning, $\mathrm{AC}$ microgrids were evolved, as the conventional power systems were dominated by the AC form. However, power generations from various DERs, such as photovoltaic systems, are DC power, so are modern electrical loads and energy storage systems. Those DC technologies are integrated with the existing AC systems through converters, which would expend more component costs and increase power losses. Moreover, it would add more power quality problems. According to those issues, DC microgrids, which are considered feasible to be implemented for commercial facilities [3], are proposed as a better alternative for DERs. DC microgrids also offer more technical and economic benefits compared to AC microgrids [4]. Since the utilization of AC power is still required, the integration of $\mathrm{AC}$ and DC microgrids is proposed, and this emerges the concept of hybrid AC/DC microgrids $[5,6]$.

Control of microgrids becomes a critical issue for ensuring reliable operation of the microgrid. A variety of research has been conducted particularly on the subject of the control system and power management in order to improve the system stability [7]. Each AC and DC microgrid has different hierarchical controls, but those could be generalize into three levels in reference to the hierarchical control standard of international society of automation (ISA)-95: (1) the primary control is based on the droop method, including an output-impedance virtual loop; (2) the secondary control allows the 
restoration of the deviations produced by the primary control; and (3) the tertiary control manages the power flow between the microgrid (MG) and the external electrical distribution system [8].

In hybrid AC/DC microgrids, $\mathrm{AC}$ and $\mathrm{DC}$ buses are connected through interlink AC/DC bidirectional converters (ICs). The IC should be able to control and manage power properly in both operating mode, grid-connected mode and stand-alone mode $[9,10]$. Operating the microgrid in stand-alone mode would lead to more challenges, particularly when the imbalance of generation and consumption happen because of flexible load and DERs. Various droop control methods have been proposed to maintain the system stability by sharing power between AC and DC subgrids, as in [11]. Incorporating an energy storage system into the IC will improve its control performance; meanwhile, DC link capacitors support the voltage regulation, as in [12].

The contribution of this paper is proposing a coordination control strategy of IC to maintain secure operation of the microgrid system in terms of frequency and voltage regulation. It is assumed that a battery energy storage system (BESS) is installed in the DC microgrid for voltage support of the corresponding bus by charging or discharging, controlled by a DC/DC bidirectional converter. When the microgrid gets into the stand-alone mode, the BESS can provide an amount of power for the weak portion of the microgrid through the IC. However, active power support cannot be sustained because of the limitation of the state of charge (SOC) level of BESS. The IC controller needs to include the method to deal with the physical limits of the SOC of the BESS. In this circumstance, the weak portion of the microgrid might experience the severe degradation of system security. The last countermeasure that can be adopted is load shedding for secure operation, and the IC controller also needs to take into account the load shedding scheme. The proposed coordination control strategy between the IC and BESS converters can facilitate a smooth transition of the power transfer between AC and DC subgrids in stand-alone mode for secure operation, using the available resources and the last resort action of load shedding within the feasible operational region of BESS.

\section{Hybrid AC/DC Microgrid Model}

\subsection{System Configuration}

A simple model of a hybrid AC/DC microgrid is illustrated as in Figure 1. In the AC microgrid, the power sources are from a 60-kilo volt ampere (kVA) diesel generator set and a 30-kW wind turbine with doubly-fed induction generator (DFIG). The AC load is composed of static loads and an induction motor with a total of $100 \mathrm{~kW}$ and 25 kilo volt ampere reactive (kVAR) and equipped with a capacitor bank to maintain reactive power in the AC load bus. The DC microgrid consists of a DC load of $20 \mathrm{~kW}$. A BESS with a rating of $20 \mathrm{~kW}$ is connected to the DC bus through a bidirectional DC/DC converter. The AC and DC microgrid are connected through an IC. The hybrid microgrid is modelled using PSCAD to simulate system operations and controls.

During normal operation, the AC microgrid is connected to the utility grid. The system stability is maintained well under this mode because of the sufficient power supplied by the utility grid. Meanwhile, during stand-alone mode, the circuit breaker (CB) that connects the utility grid to the microgrid opens. Each DER and energy storage should ensure the system stability. Those units are supported by IC, which manages the power sharing among AC and DC sources and between both systems.

As shown in Figure 2, IC is comprised of a DC/DC bidirectional converter connected to a three-phase inverter/rectifier. Since the converter is connected to a three-phase inverter/rectifier, a galvanic isolation is needed as protection from a short circuit. The converter is designed to be able to be connected with $750 \mathrm{~V}$ for the inverter side and $500 \mathrm{~V}$ for the DC load side. 


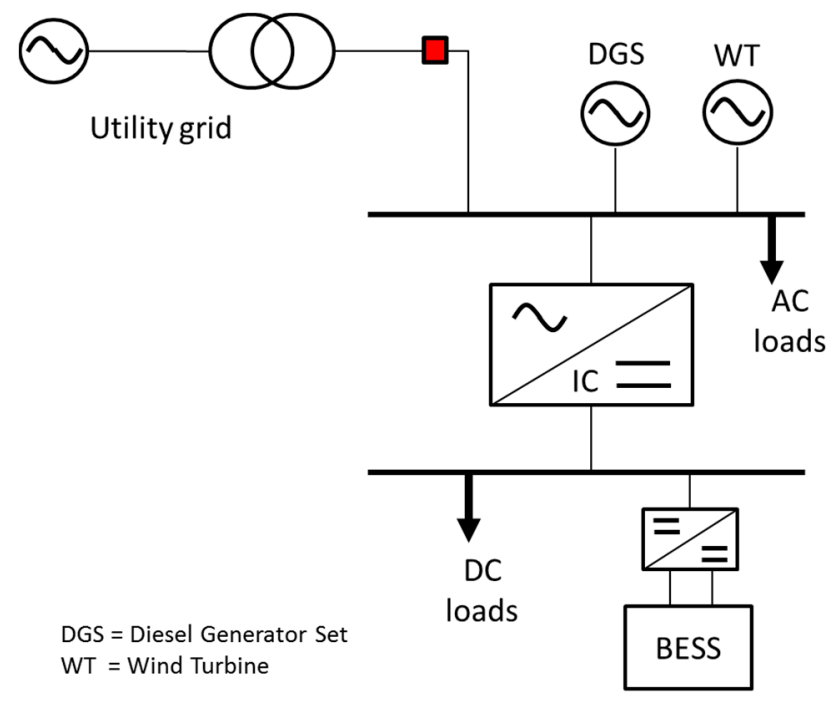

Figure 1. Hybrid AC/DC microgrid model. IC, interlink converter; BESS, battery energy storage system.

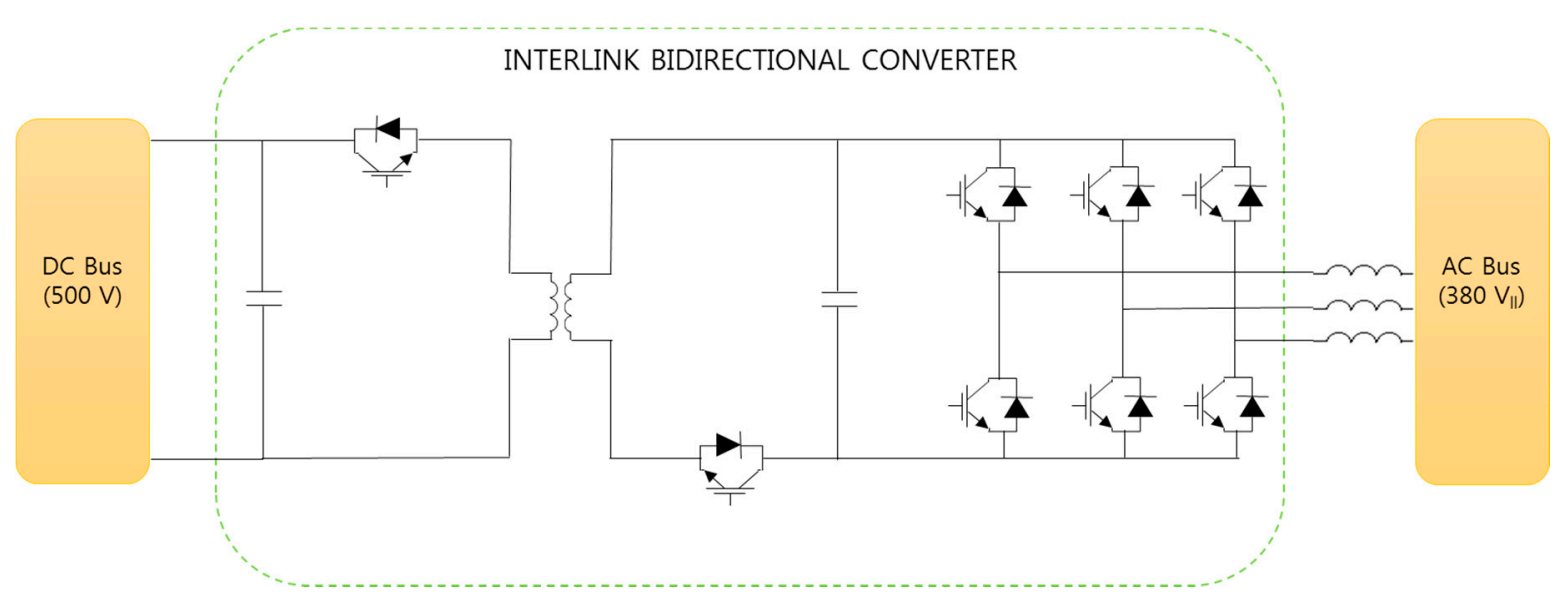

Figure 2. IC configuration.

\subsection{Diesel Generator Set Governor Control}

A diesel generator set consists of a synchronous generator, an excitation system and a diesel engine with a governor. The diesel engine and the synchronous generator rotate at the same speed, i.e., $1800 \mathrm{rpm}$, and no gearbox is used. Figure 3 illustrates the governor control scheme of the diesel generator. While the microgrid is running in stand-alone mode, the diesel generator will maintain the frequency and voltage of the system. Thus, it requires a proper control system.

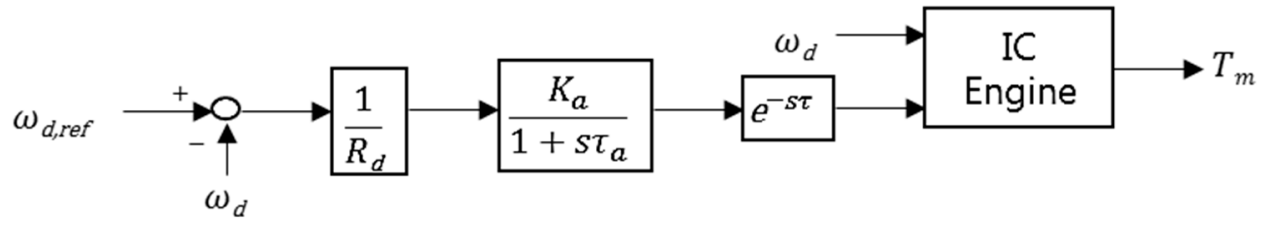

Figure 3. Governor control of the diesel generator set. 


\subsection{Wind Turbine Governor Control}

The wind turbine model in PSCAD comprises a wind source, a turbine aerodynamic model and an electrical machine. A doubly-fed induction generator (DFIG) is used as the electrical machine. According to the convention of the induction machine, the input mechanical torque is negative. The turbine type is Wind Turbine Governor MOD 2; it is a horizontal-axis turbine with three blades. The output power from a wind turbine is given by (1).

$$
P_{w}=0.5 \rho v_{w}^{3} A C_{p}(\lambda, \beta)
$$

The power control mechanism is using a pitch controller. The initial pitch angle and wind speed are inputs to this module. Figure 4 is the wind turbine governor transfer function.

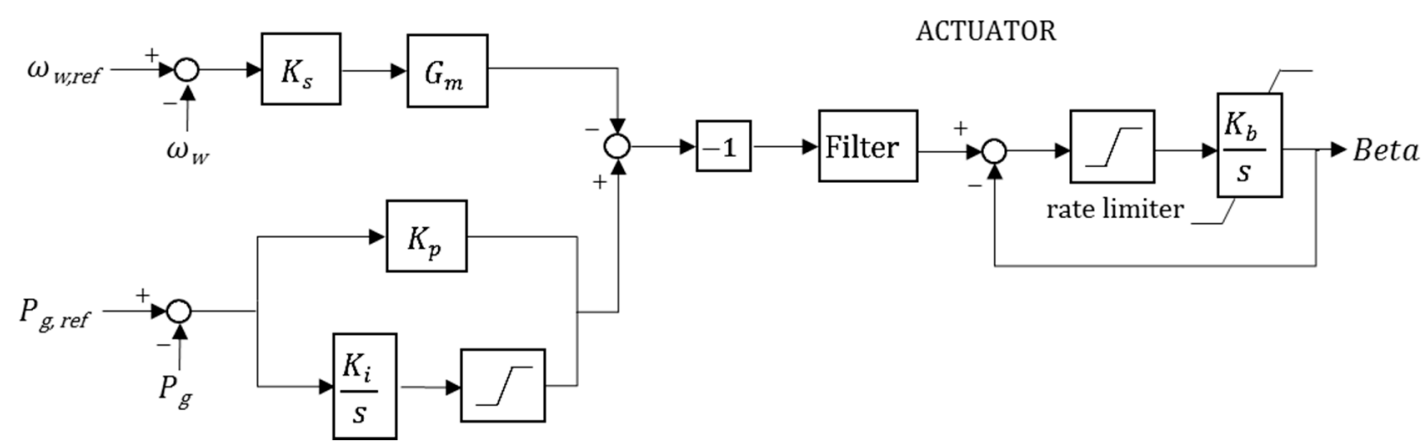

Figure 4. Wind governor transfer function.

\subsection{Modeling of the Battery Energy Storage System}

The electrical equivalent model of the lithium-ion battery is constructed from a state of charge (SOC)-dependent voltage source followed with one resistor and two resistor-capacitor elements, as shown in Figure 5. The open circuit voltage and resistances are defined with SOC as follows [13]:

$$
\begin{gathered}
E_{m}=0.035582 \times \mathrm{SOC}+47.698 \\
R_{0}=0.0401 \times e^{-0.0908 \times \mathrm{SOC}}+0.03655 \\
R_{1}=3.041 \times 10^{-10} e^{0.1874 \times \mathrm{SOC}}+0.03437 \\
R_{2}=0.101 e^{-0.02025 \times \mathrm{SOC}}+0.02188 \\
\% \mathrm{SOC}=1+\frac{\int I_{\text {bat }} d t}{Q_{\text {cap }}}
\end{gathered}
$$

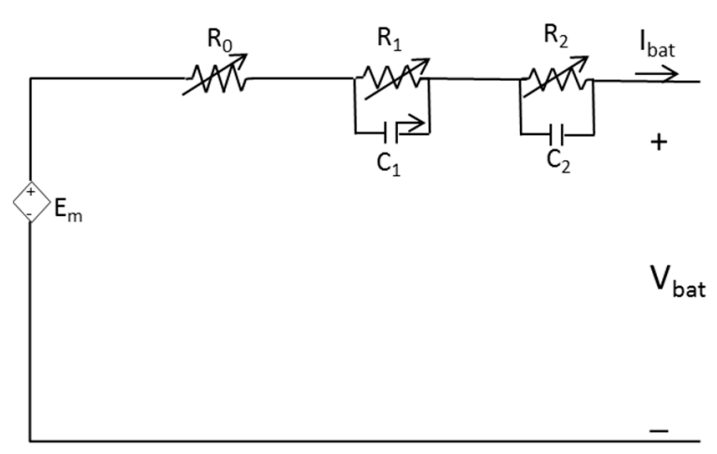

Figure 5. Lithium-ion battery model. 
Battery SOC is limited from $15 \%$ as the minimum level to $80 \%$ as the maximum level. The terminal voltage of the battery is derived from Equation (7) and its multiplication with battery current results' output power battery as in Equation (8):

$$
\begin{gathered}
V_{b a t}=E_{m}-I_{b a t} \times Z_{t o t} \\
P_{b a t}=V_{b a t} \times I_{b a t}
\end{gathered}
$$

\section{System Operation of Interest}

In the hybrid AC/DC microgrid, the IC has an important role, particularly when the microgrid is disconnected from the utility grid. Proper control and a power management system are required for the IC to manage the flow of energy from one subgrid to the other. The power management of IC control is expected to manage a bidirectional power flow between both subgrids. The hybrid AC/DC microgrid could be operated in grid-connected mode and stand-alone mode. Under grid-connected mode, the hybrid microgrid is connected with the utility grid, which acts as the slack bus. The diesel generator provides active and reactive power; meanwhile, the wind turbine generator outputs active power and consumes reactive power in the system. Furthermore, the utility grid supports a portion of power to regulate $\mathrm{AC}$ system frequency and voltage magnitude, while the voltage of the DC subgrid is regulated by the IC and BESS. In the case of systems having DC sources connected to the DC bus, an amount of power will be supplied. Normally, the IC manages the power balance between both subgrids.

In stand-alone mode, if the output power of sources in one subgrid cannot satisfy its load demand, the security of the system might be deteriorated. Thus, the IC requires a proper control strategy to manage load sharing among the sources for power balance. The buses experiencing a lack of power supply would take power from other buses with surplus power. In this situation, the IC would act as a power supplier for the weak subgrid and as a load for the other. In microgrids with dispersed sources, the local control method is desirable, particularly under stand-alone operation. Thus, most of the microgrids implement a droop control strategy, which does not require any communication among the sources, and the information of local frequency and voltage is used for power sharing. Basically, the frequency of the AC system and the voltage of the DC network are affected by the balancing mechanism of active power, and the voltage in the AC network is linked to that of reactive power.

\section{Droop Control Strategies in an Individual Microgrid}

\subsection{Droop Control of AC Microgrid}

Frequency variation is caused by the power balance of an AC microgrid. The droop control scheme is usually implemented on the sources to regulate the system frequency in order to obtain proper power sharing. When frequency deviations occur in the system, the droop control will restore it by the change in active power output of the controlled sources, defined by (9). The locally-measured system frequency is compared to the reference value, and the error is multiplied by a gain constant to obtain the droop control.

$$
\left(P_{\text {max }, a c}-P_{0, a c}\right)=K_{p, a c} \times\left(f_{0, a c}-f_{\text {min }, a c}\right)
$$

A similar strategy also could be applied to regulate $\mathrm{AC}$ system voltage by the change in reactive power output. For the regulation, the voltage-reactive power (V-Q) droop characteristic of (10) is used. Three-phase terminal voltages are measured, and the magnitude will be compared to its reference value. The voltage deviation is multiplied by a gain constant to obtain the droop control. In Figures 6 and 7 , the frequency-active power (f-P) and V-Q droop characteristic curves are shown.

$$
\left(Q_{\max , a c}-Q_{0, a c}\right)=K_{q, a c} \times\left(V_{0, a c}-V_{\min , a c}\right)
$$




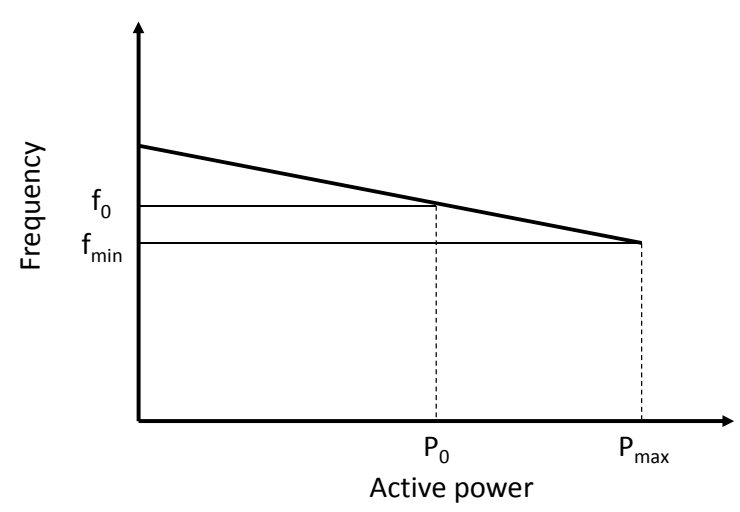

Figure 6. f-P droop characteristic in the AC microgrid.

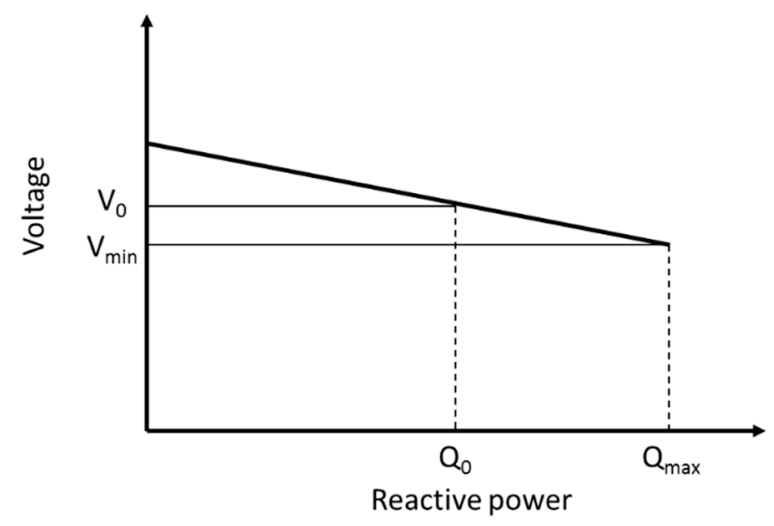

Figure 7. V-Q droop characteristic in the AC microgrid.

\subsection{Droop Control of the DC Microgrid}

In the DC microgrid, the active power sharing is managed by the output voltage magnitude of converters. There is no control scheme for reactive power sharing and frequency. The droop control scheme for voltage regulation is defined by (11) with Figure 8 .

$$
\left(P_{\max , d c}-P_{0, d c}\right)=K_{p, d c} \times\left(V_{0, d c}-V_{\min , d c}\right)
$$

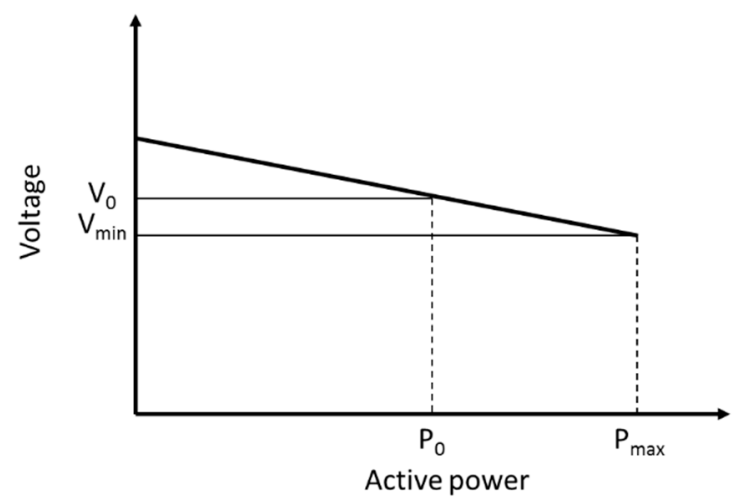

Figure 8. Voltage-active power (V-P) droop characteristic in the DC microgrid. 


\section{Proposed Droop Control Strategy}

Hybrid microgrids need different droop control schemes compared to individual AC or DC microgrids. The IC needs to manage the bidirectional power flow between AC and DC subgrids. Both subgrids have distinct droop characteristics, and the IC should have a proper coordination control strategy for power sharing. While one subgrid experiences excessive power generation, the IC should be able to get the power injection to the proper level to mitigate the problem. At that time, the IC acts as a supplier for one subgrid and as a load for the other.

In this proposed droop control strategy, active power sharing will be performed by enforcing the frequency deviation on the AC subgrid to be equal to the bus voltage deviation on the DC microgrid. The difference of both values in per unit (p.u.) will be the input of the proportional controller with gain $1 / R_{p}$ to generate a new active power reference transferred by the IC. When using a stiff droop constant, the IC tried to reduce the deviation of the frequency of the AC subgrid and the voltage of DC subgrid from their nominal values before other DERs with primary controllers. However, it is not recommended to use a much lower value of $R_{p}$ for the IC from those of the DERs, because the main sources of the additional active power are the DERs.

$$
\begin{gathered}
\Delta f=\frac{f_{\text {nom }}-f_{m}}{f_{\text {nom }}} \\
\Delta V_{d c}=\frac{V_{d c, n o m}-V_{d c, m}}{V_{d c, n o m}} \\
\Delta P=\left(\Delta f-\Delta V_{d c}\right) \times \frac{1}{R_{p}}
\end{gathered}
$$

As shown in Figure 9 for the proposed droop control scheme of the IC, positive error means power is flowing from the DC subgrid to the AC subgrid, meanwhile negative error means power flow from the AC subgrid to the DC subgrid. Figure 10 illustrates the power setting point of the IC and its positive direction. Under grid-connected mode, the installed BESS in the DC subgrid might not discharge any power, but charge power if SOC is not within the acceptable range. When the SOC level reaches its maximum limit, the battery will be in idle mode; this means that it does not charge nor discharge power. The DC load demand is supplied by sources in the AC subgrid, by the transfer of power through the IC. This condition causes the transferred power of the IC to be added by the initial active power, as defined in (15).

$$
P_{I C}^{*}=P_{I C, 0}+\Delta P
$$

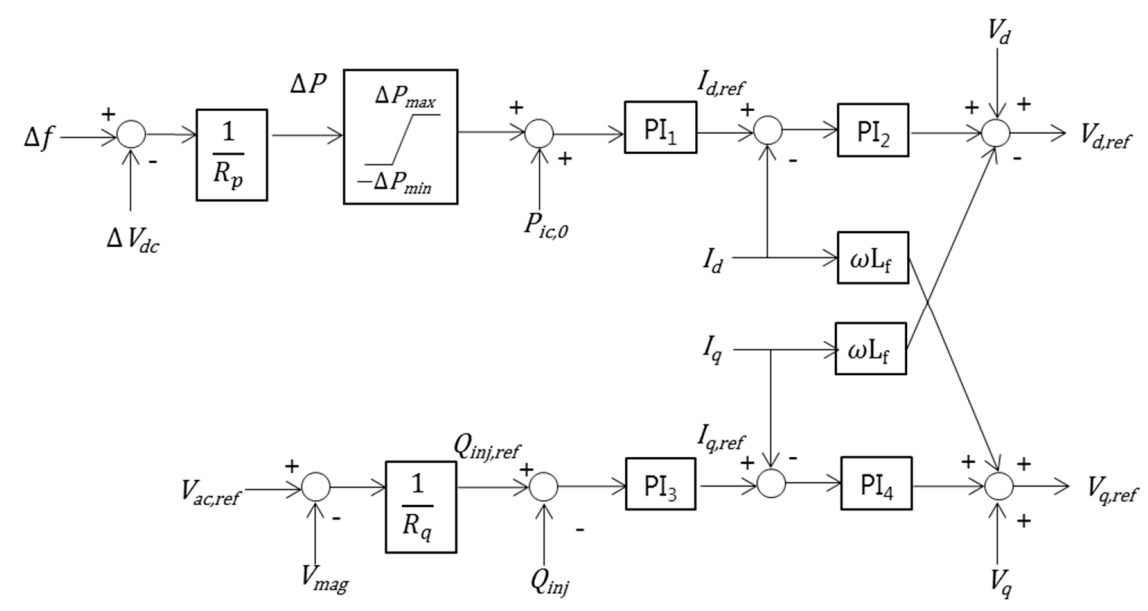

Figure 9. Proposed droop control scheme for the hybrid AC/DC microgrid. 


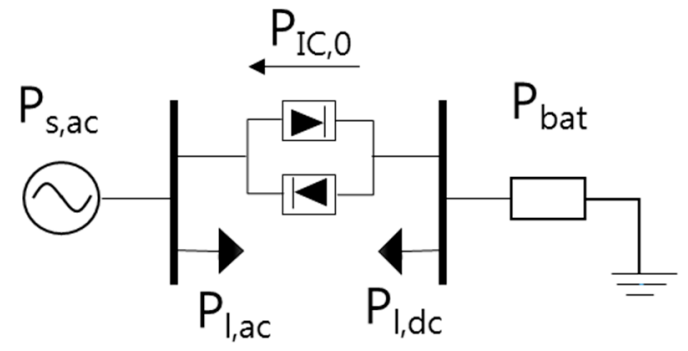

Figure 10. IC initial active power flow.

In the proposed control scheme, as in Figure 9, the change in the active power transfer through the IC, $\Delta P$, needs to be limited based on the SOC of the battery, because the battery in the DC subgrid can respond more quickly than other resources, and it can behave like a source and a load. In Figure 11, the limiting parameters of $\Delta P_{\max }$ and $\Delta P_{\min }$ depend on the level of SOC, and discharging power is denoted by a positive sign and charging power by a negative one. Power flow from the DC to the AC subgrid is assumed as positive power transfer, as in Figure 10. Under those conditions where positive $\Delta P$ is required, the upper level of $\Delta P$ is limited by $\Delta P_{\max }$ when the battery SOC is higher than its minimum level. However, $\Delta P_{\max }$ is reduced to zero when the battery SOC is quite close to $S O C_{\min }$, as in Figure 11. Otherwise, the change in power injection with a negative sign is needed, and the lower level of $\Delta P$ is limited by $-\Delta P_{\min } ; \Delta P_{\min }$ is reduced to zero when the battery SOC reaches its maximum level.
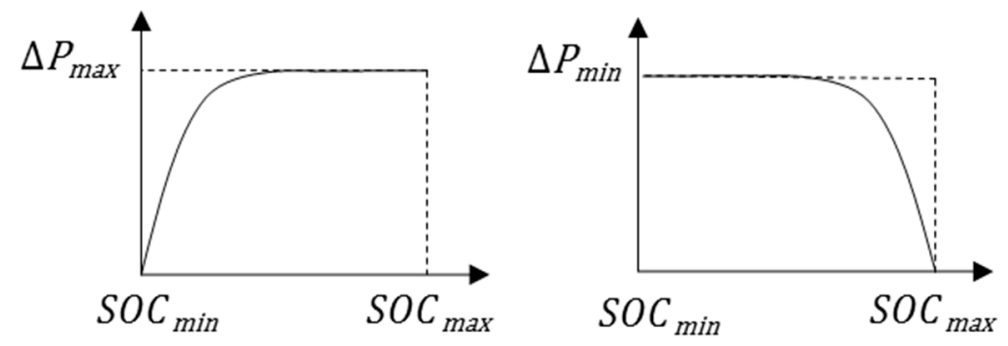

Figure 11. Active power injection limited by the SOC.

In order to obtain current tracking reference $I_{d r e f}$, injection $P_{I C}^{*}$ will be controlled through a proportional-integral (PI) controller. The error of $I_{d}$ from its reference value then will be regulated by another PI controller to achieve $V_{\text {dref }}$.

Control of reactive power sharing for a hybrid microgrid is similar to the AC microgrid scheme. Current reference, $I_{\text {gref }}$, is produced by the PI controller with $Q_{I C}^{*}$ as the input. There is no initial reactive power value, since there is no reactive power transfer under grid-connected mode. $Q_{I C}^{*}$ will become zero if power flows from the AC to the DC subgrid since the DC subgrid does not require reactive power. Current reference $I_{q, \text { ref }}$ is generated by the PI controller with $Q_{I C}^{*}$ as the input. $V_{\text {qref }}$ is obtained through another PI controller, which manages the error of $I_{q}$. The direct-quadrature (d-q) outputs from the PI controllers are transformed back to three phase $(a-b-c)$ form to generate the signal for the pulse width modulation (PWM) converter.

$$
\Delta Q=\left(V_{a c, n o m}-V_{a c, m}\right) \times \frac{1}{R_{q}}
$$

\section{Coordination Control of IC and the BESS Converter}

Under normal operation, power balance in the whole system is guaranteed because of the support from the utility grid. Meanwhile, if one microgrid experiences a lack of power supply under 
stand-alone operation, the IC needs to manage the power sharing between both subgrids in order to maintain system security. Besides, the BESS converter should work properly by charging or discharging actions, regarding the system requirement.

The power management scheme for the proposed hybrid microgrid model under stand-alone operation is shown in Figure 12. The scheme determines the power transfer direction controlled by IC and battery operation mode controlled by the battery converter. The battery as a grid-forming unit has to handle the power variations that take place in the entire hybrid microgrid [14]. $P_{\text {net }}$ is the active power difference among the sources and demand load in the microgrid model, as in (17), and it then represents the active power amount that needs to be supplied or consumed by the battery.

$$
P_{n e t}=\sum P_{s, a c}-\sum P_{l, a c}-\sum P_{l, d c}
$$

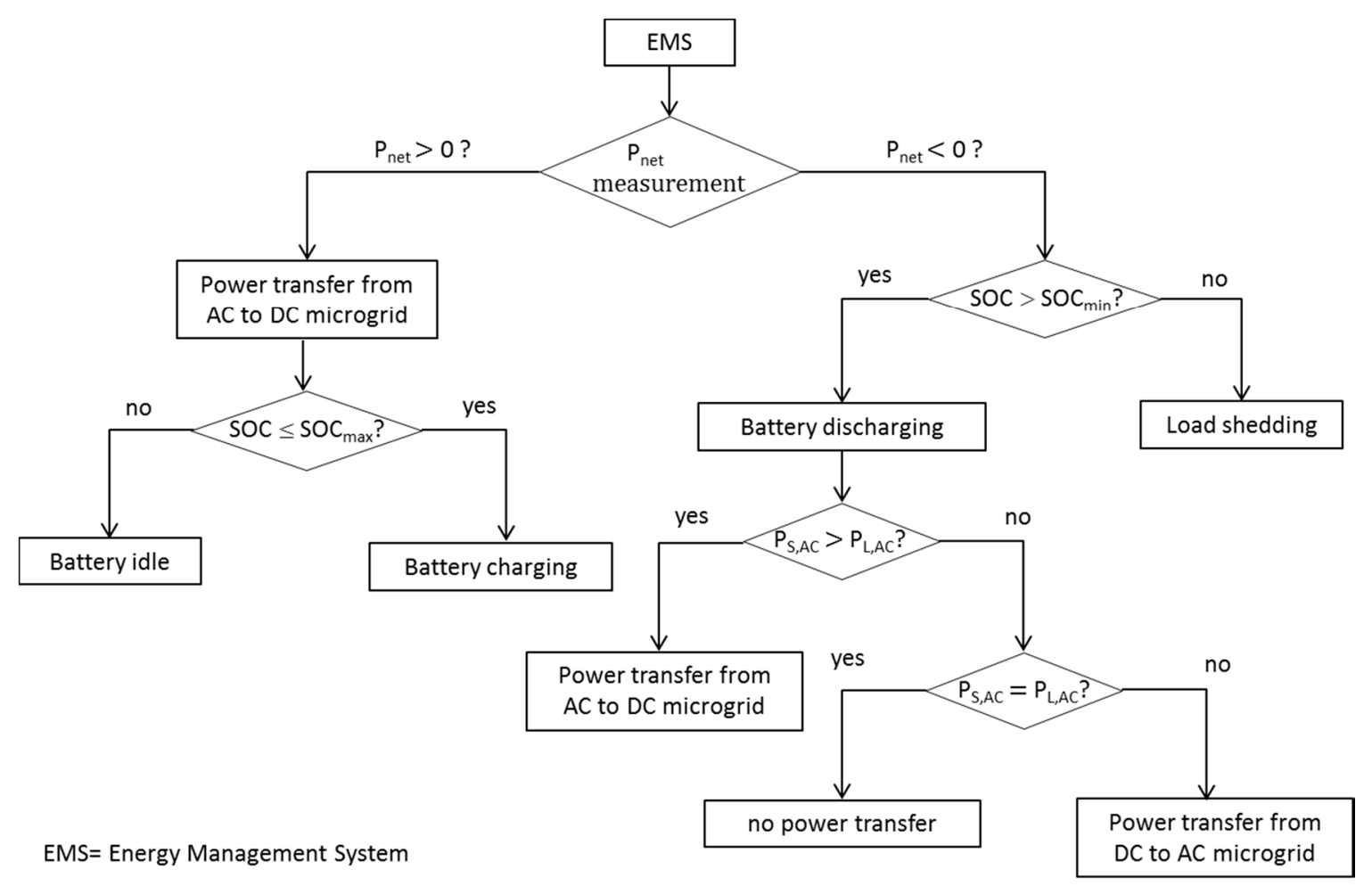

Figure 12. Power management under stand-alone operation.

Under stand-alone operation, the power management scheme is crucial for secure system operation. As in Figure 12, the battery SOC and the imbalance between generation and load in the whole microgrid determine the operation mode of the battery and the direction of power injection through the IC. If the sources' output power is more than the load demand, the IC will enforce the increase in transfer power to the DC subgrid since the sources are only installed in the AC subgrid in the system configuration. When the battery SOC level has room to charge, the battery will be in charging mode. However, if the SOC level is quite close to the SOC maximum limit, the battery will be in idle mode, and some other countermeasures need to be taken.

In the case where the sources could not satisfy the load demand in the whole microgrid system and the SOC level has room to discharge, the battery will be in discharging mode. If the sources cannot support the load demand in the whole system, the power management scheme needs to consider two cases; if the net power in the AC subgrid is negative, the IC would transfer the surplus power to the AC subgrid. If the AC subgrid is in the power balance condition, the IC would not change the transfer power. In both cases, the battery needs to discharge the proper amount of power, and it can be 
automatically done by the voltage regulation control of the battery converter. However, discharging cannot be sustained because of the limited capacity. As the last resort, a load shedding scheme is carried out if the SOC level is quite close to its minimum limit, and then, the microgrid is restored from its deficiency in power supply.

In some particular cases, the system frequency is not able to be restored, even though the planned load shedding is applied. This is caused by the power injection to the DC subgrid and the droop control action for the DC voltage regulation; in other words, the IC needs to share some amount of power with the DC subgrid. Thus, the DC voltage deviation and initial setting point of active power transfer need to be limited according to the AC subgrid frequency deviation, following the equations below.

$$
\begin{gathered}
\Delta V_{d c}^{\prime}=\Delta V_{d c}\left(1-k_{f} \times \Delta f\right) \\
P_{I C, 0}^{\prime}=P_{0}\left(1-k_{f} \times \Delta f\right)
\end{gathered}
$$

By applying the limitations above, Equations (14) and (15) change into (20) and (21). Furthermore, in the scheme, a certain frequency deadband is employed to exempt the small frequency deviation.

$$
\begin{gathered}
\Delta P=\left(\Delta f-\Delta V_{d c}^{\prime}\right) \times \frac{1}{R_{p}} \\
P_{I C}^{*}=P_{I C, 0}^{\prime}+\Delta P
\end{gathered}
$$

In the DC subgrid, the power imbalance causes the voltage bus to deviate from its nominal value. The connection between BESS and the DC bus is interfaced by the bidirectional DC/DC converter that will take action once the DC voltage deviates. When the DC link voltage drops due to the lack of power supply, the BESS controller will provide the change in current reference, flowing to the DC bus. In this condition, the converter acts as a boost converter, and the battery discharges power.

Otherwise, in the case where there is excess power output from AC sources and the IC gets the amount of power to the DC subgrid, the DC bus voltage might be increased. In this case, the controller of the BESS will provide the new current reference point, so that the battery absorbs the power from the DC bus. Then the DC/DC converter behaves as a buck converter, and the battery is in charging mode. The control scheme for the BESS converter is shown in Figure 13, and it was originally from [15].

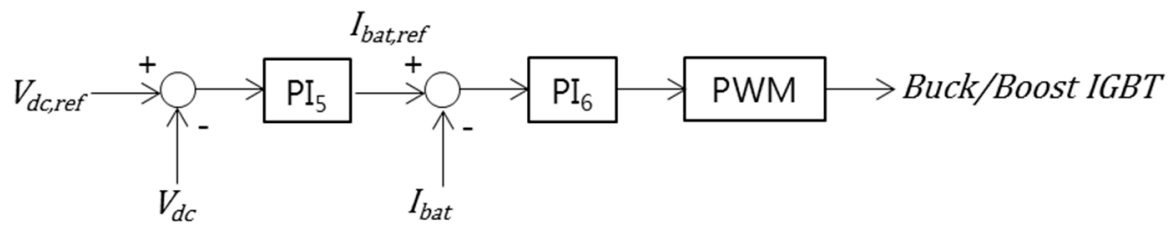

PWM $=$ Pulse Width Modulation

IGBT = Insulated-Gate Bipolar Transistor

Figure 13. Control scheme of the battery converter.

\section{Simulation Results}

In normal operation, the AC and DC microgrids are usually in the secure operation condition due to the power balance that can be made because of the external system support. In the simulation, nominal values of frequency, AC voltage and DC voltage were defined as $60 \mathrm{~Hz}, 380 \mathrm{~V}$ (line to line) and $500 \mathrm{~V}$, respectively. Since there were no power sources in the DC subgrid, the DC load demand was mainly supplied by the AC sources, and the IC initially transferred power from the AC subgrid to the DC subgrid during grid-connected mode. The rated active and reactive power for the IC were $20 \mathrm{~kW}$ and $10 \mathrm{kVAR}$, respectively, and the IC initial setting point was determined around $20 \mathrm{~kW}$ transferring 
power from the $\mathrm{AC}$ to the $\mathrm{DC}$ microgrid. In the simulation, $R_{p}$ and $R_{q}$ were all set to 0.05 for the IC droop controller.

In the first case, it was assumed that the battery SOC approached its minimum level, $15.0 \%$. The AC sources and utility grid supplied power around $134 \mathrm{~kW}$ and $23 \mathrm{kVAR}$, and the AC load demand was around $105 \mathrm{~kW}$ and $23 \mathrm{kVAR}$. DC load demand was $19 \mathrm{~kW}$. Since the battery had very low SOC and the load demand was rather high, the DC bus voltage slightly decreased to $487.5 \mathrm{~V}$, and hence, the droop control for the IC provides the corresponding power setting point. Thus, the active power of $27 \mathrm{~kW}$ was transferred from the AC subgrid to the DC subgrid. According to (17), the difference of the IC power and DC load was equal to the amount of charging or discharging power of BESS. Due to conversion and line losses, just around $5 \mathrm{~kW}$ was able to be charged by the battery. Figures 14-16 show the power generation and consumption curves of the whole elements in the AC and DC subgrids.

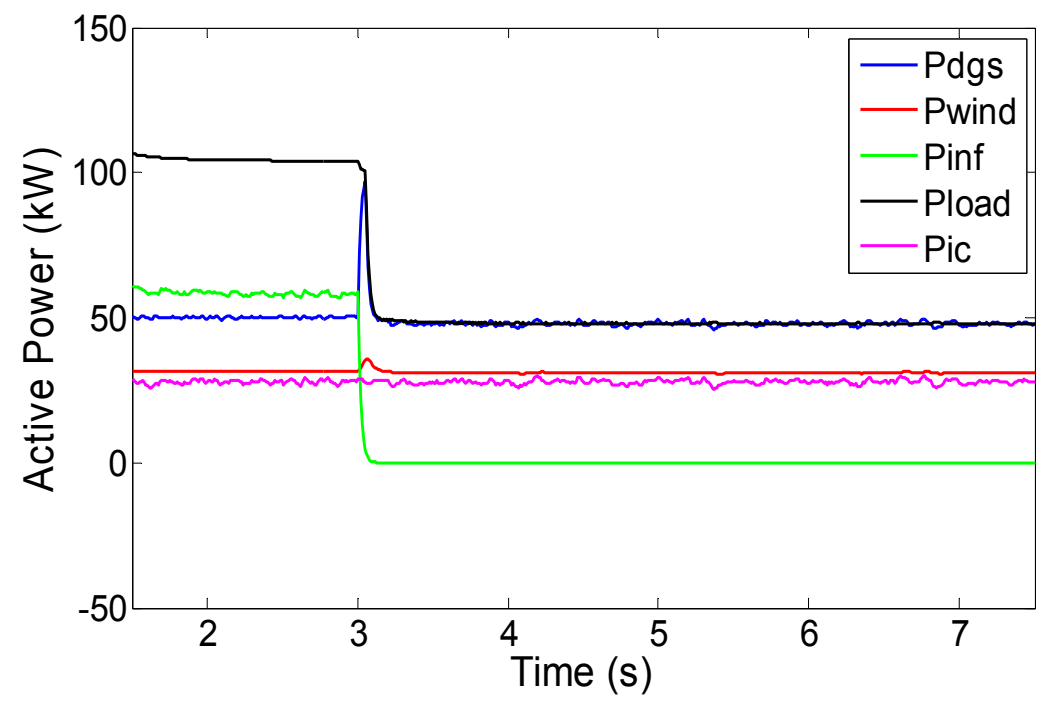

Figure 14. AC active power flow in the first case.

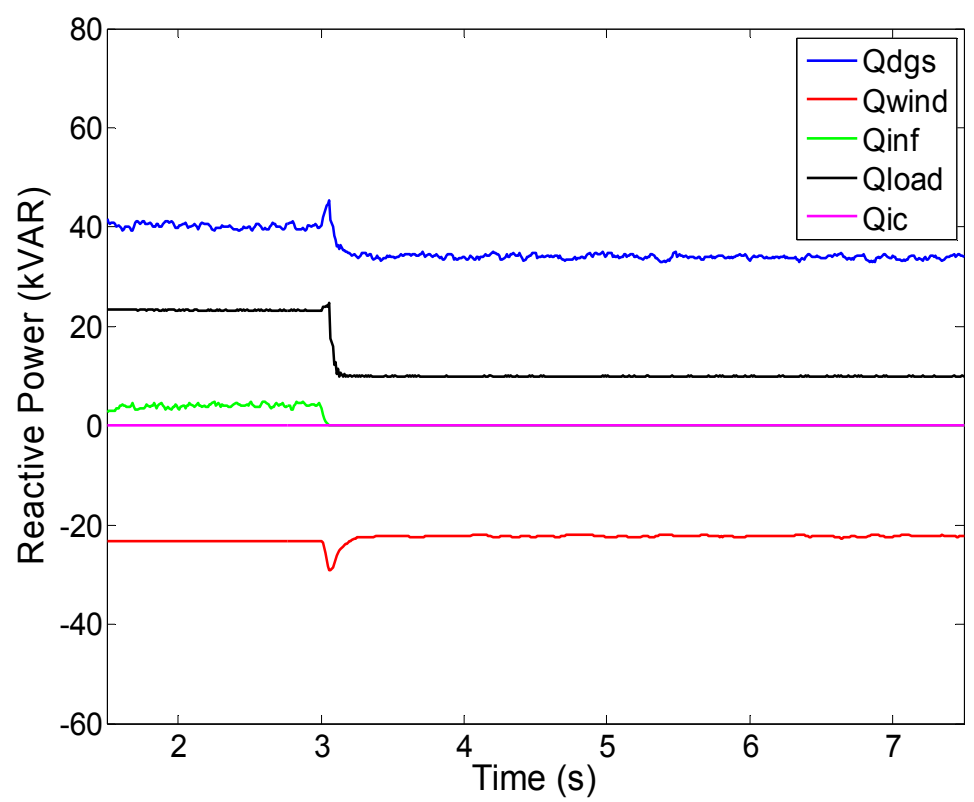

Figure 15. AC reactive power flow in the first case. 


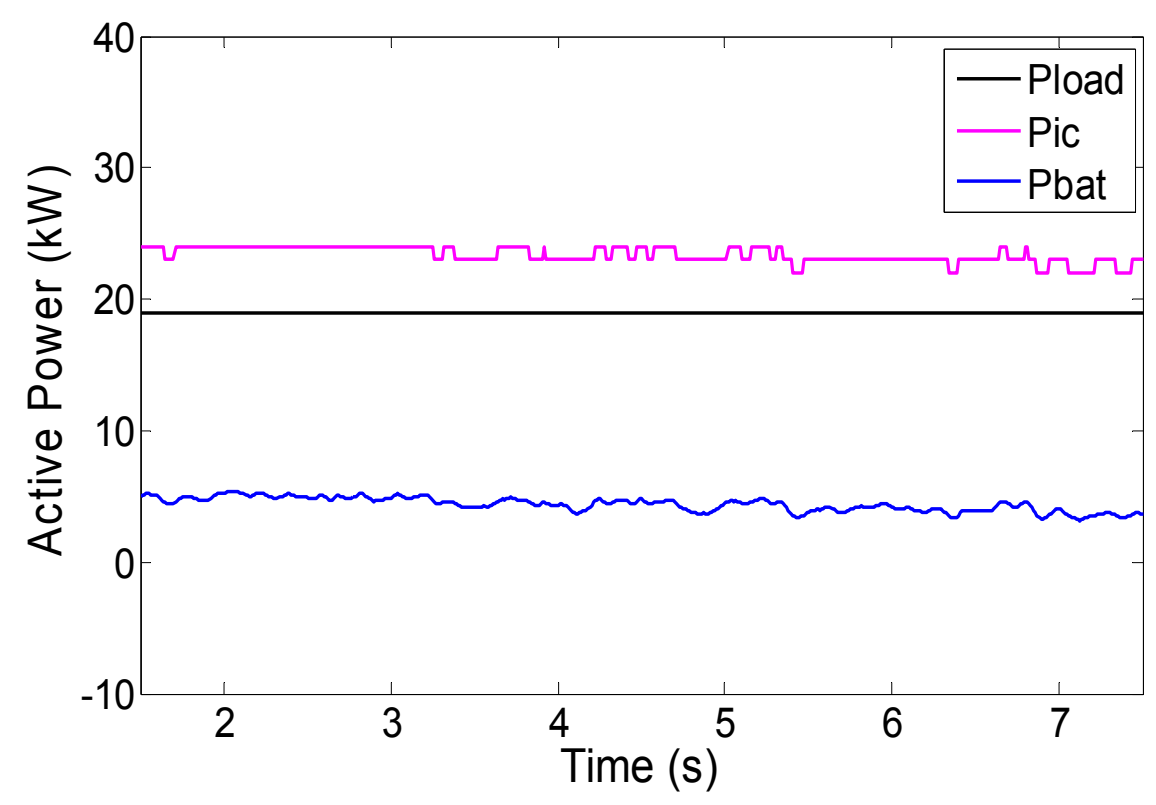

Figure 16. DC active power flow in the first case.

At $t=3 \mathrm{~s}$, the static switch that connected the AC microgrid to the utility grid was opened. The operation mode of the hybrid microgrid gets into stand-alone mode. Power support around $59 \mathrm{~kW}$ and $4 \mathrm{kVAR}$ from the utility grid was not supported anymore, and then, the frequency decreased to $59.4 \mathrm{~Hz}$ in the AC subgrid. When the operation mode was changed, the frequency kept decreasing, since there was not enough power supplying the load demand, so load shedding needed to be applied by the power management scheme, as in Figure 12, and then, the frequency got restored. The change of frequency is shown in Figure 17. In this situation, the IC tried to increase the power transfer to regulate the frequency, but that action was confined because the SOC level of the battery is close to its minimum, and hence, $\Delta P_{\max }$ is quite close to zero.

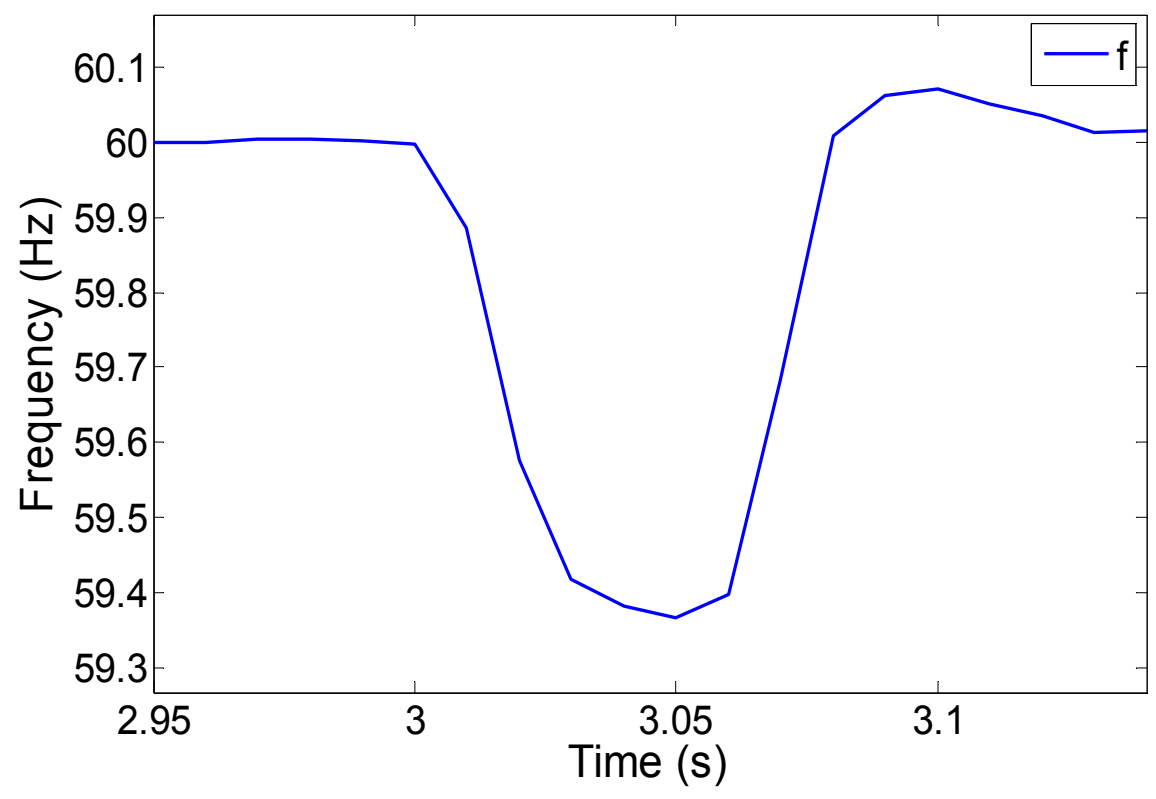

Figure 17. Frequency responses when the operation mode changed. 
While the operation mode was changing, the DC bus kept receiving the power from the AC sources, so the bus voltage was maintained within the acceptable range, as in Figure 18; meanwhile, the AC subgrid voltage slightly decreased due to the $V-Q$ droop control. Figure 19 shows the SOC curve during the simulation.

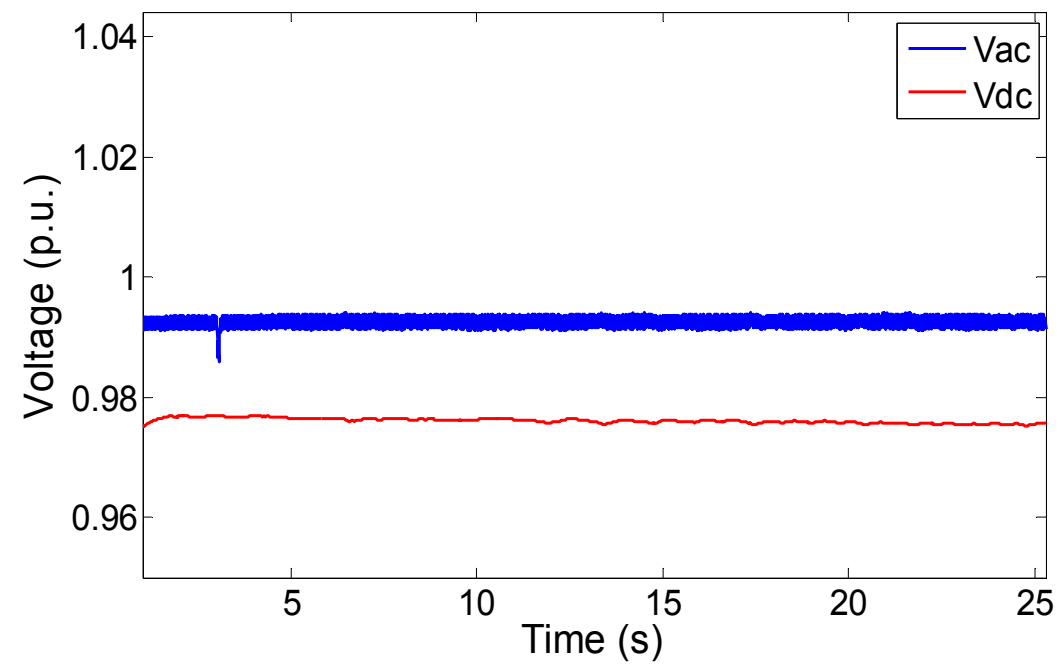

Figure 18. AC and DC voltages in the first case.

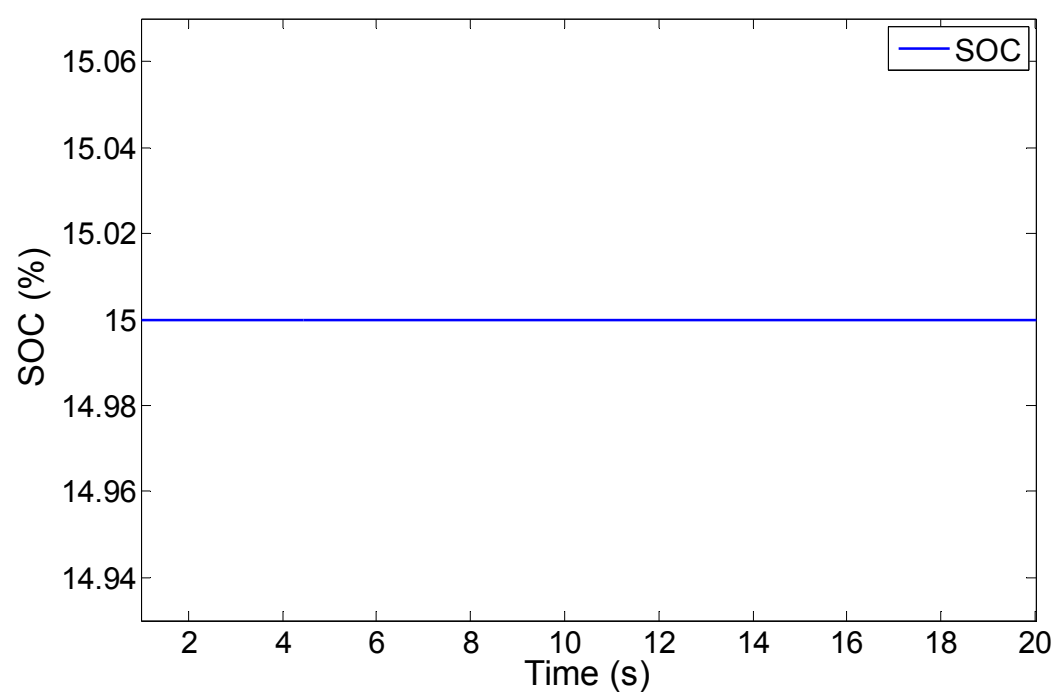

Figure 19. Battery SOC in the first case.

In the second case, the hybrid microgrid was initially operated under stand-alone mode. The battery SOC was at its maximum level, around $80 \%$. The consumption of DC load was $17 \mathrm{~kW}$; meanwhile, the AC loads were $58 \mathrm{~kW}$ and $0.5 \mathrm{kVAR}$. The AC sources generated power around $78 \mathrm{~kW}$ and $1 \mathrm{kVAR}$, so there was excess power around $3 \mathrm{~kW}$ in the AC subgrid. Since the battery SOC already reached its maximum value, the change in power through the IC, $\Delta P$, that flowed into the DC microgrid was limited by $\Delta P_{\text {min }}$, and $\Delta P_{\min }$ was set close to zero because the battery was fully charged. Thus, BESS could not charge the net power. Figures 20-22 show the power generation and consumption curves of the whole elements in the AC and DC subgrids in the simulation. 


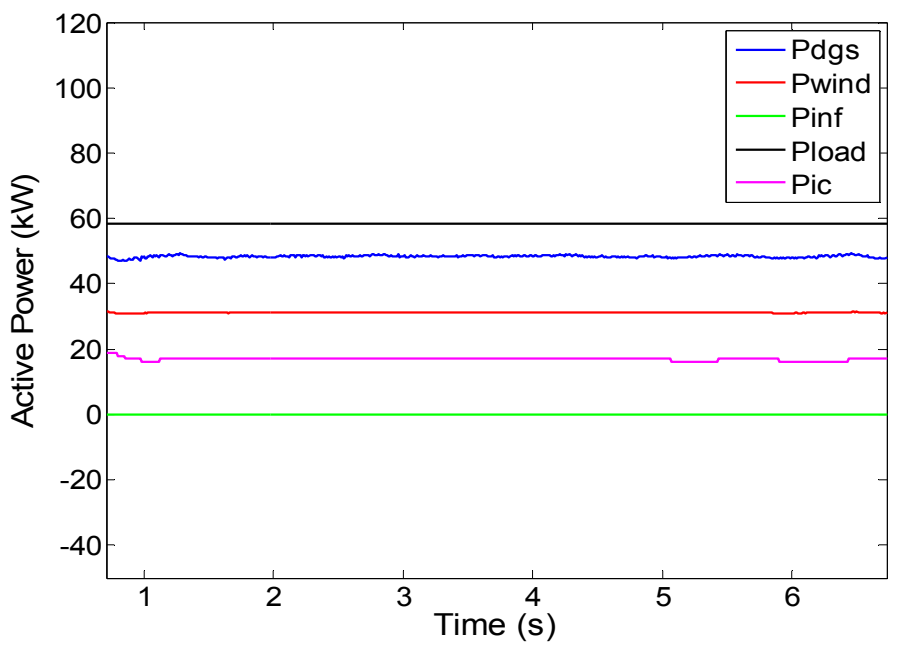

Figure 20. AC active power flow in the second case.

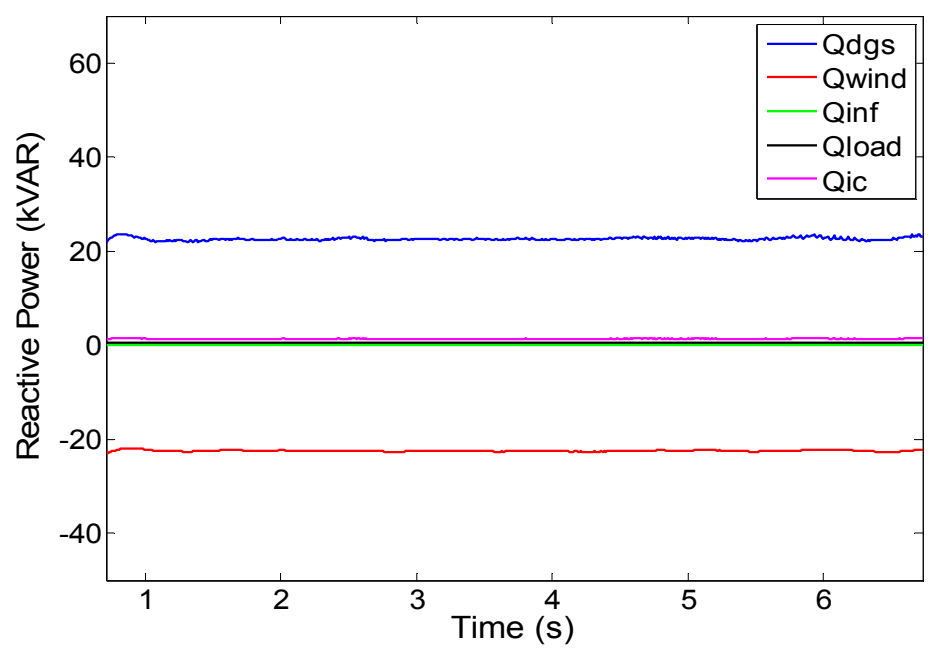

Figure 21. AC reactive power flow in the second case.

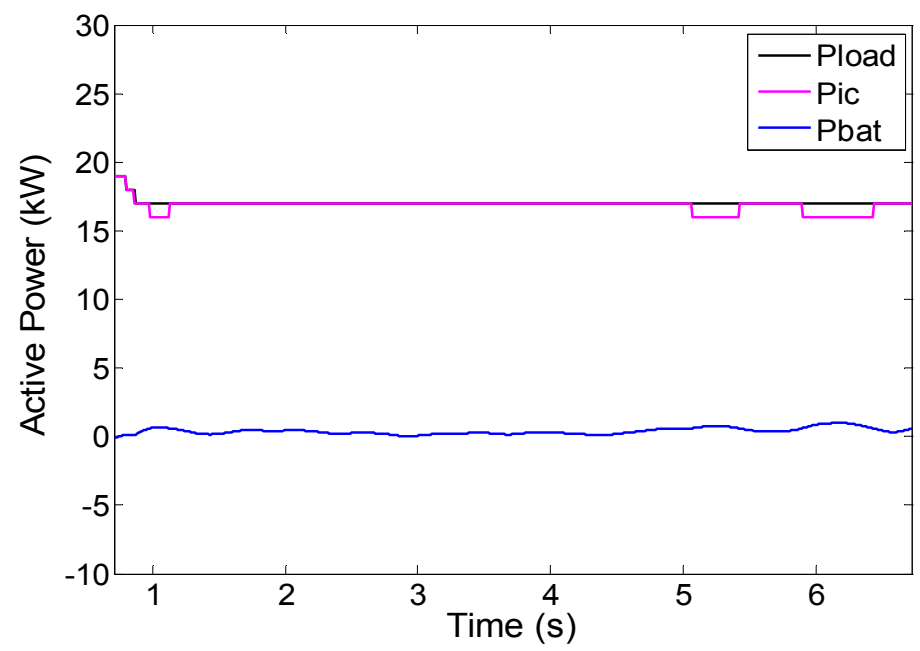

Figure 22. DC active power flow in the second case. 
In this case, from the initial setting point of $20 \mathrm{~kW}$ from the AC to the DC subgrid, the IC power finally became $17 \mathrm{~kW}$ to satisfy the DC load. In this situation, the slight increase in the AC system frequency from its nominal value occurred, as shown in Figure 23. Pertaining to the DC voltage, it was a bit higher than 1 p.u., since the DC subgrid had excess power support. The deviation of DC bus voltage was gradually reduced by the coordination control of the IC and the battery, as shown in Figure 24. Without considering the SOC limit, the power to the DC subgrid was not managed properly, compared to the proposed droop control strategy. It initially caused a higher DC subgrid voltage from the nominal value and took a longer time to regulate it. Figure 25 shows the SOC curve during the simulation. To further restore the AC system frequency back to its nominal level, some action needs to be taken, such as increasing loads or reducing power generation by the automatic governor control (AGC) action of the AC sources.

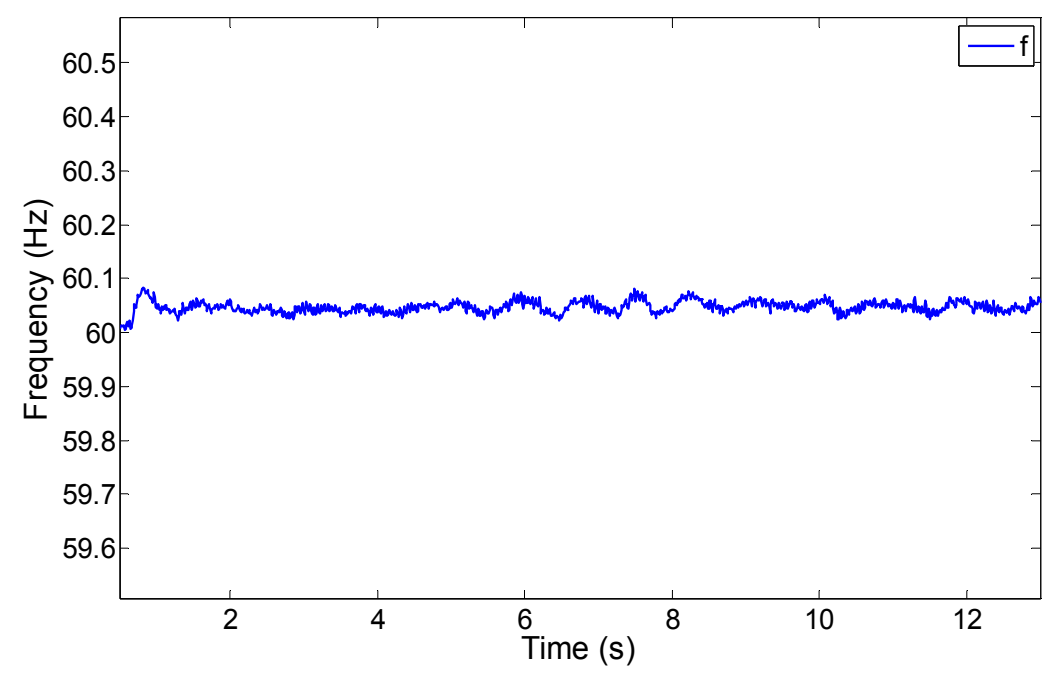

Figure 23. Frequency was slightly higher than its nominal value.

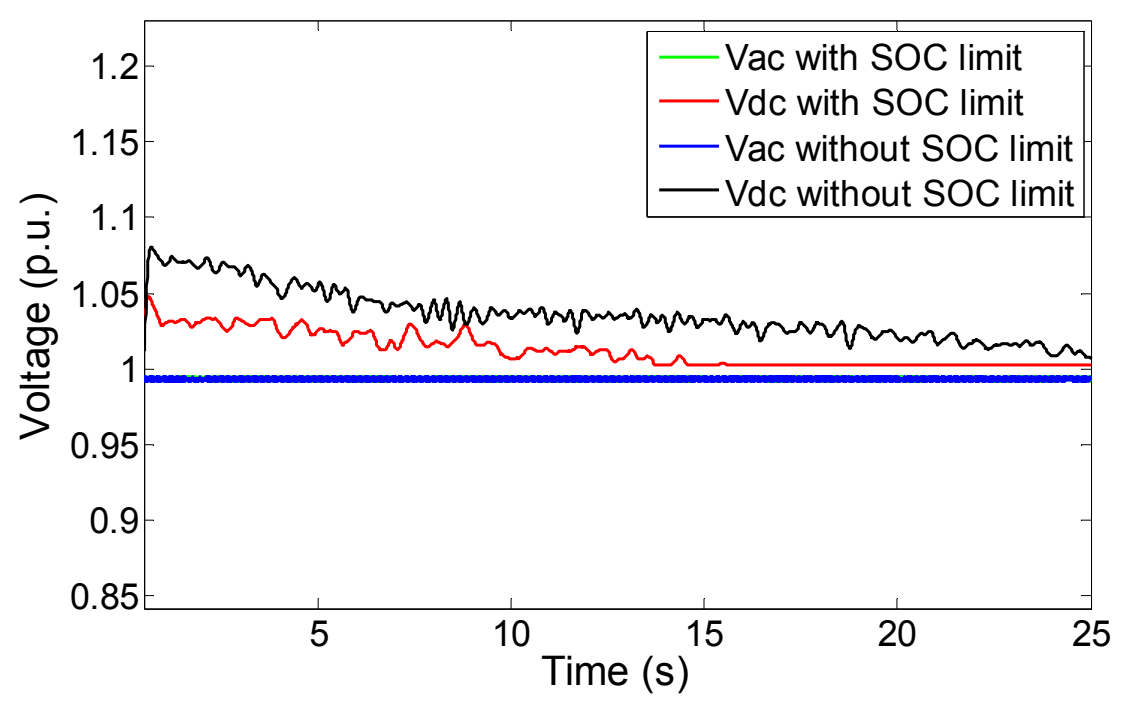

Figure 24. AC and DC voltages in the second case. 


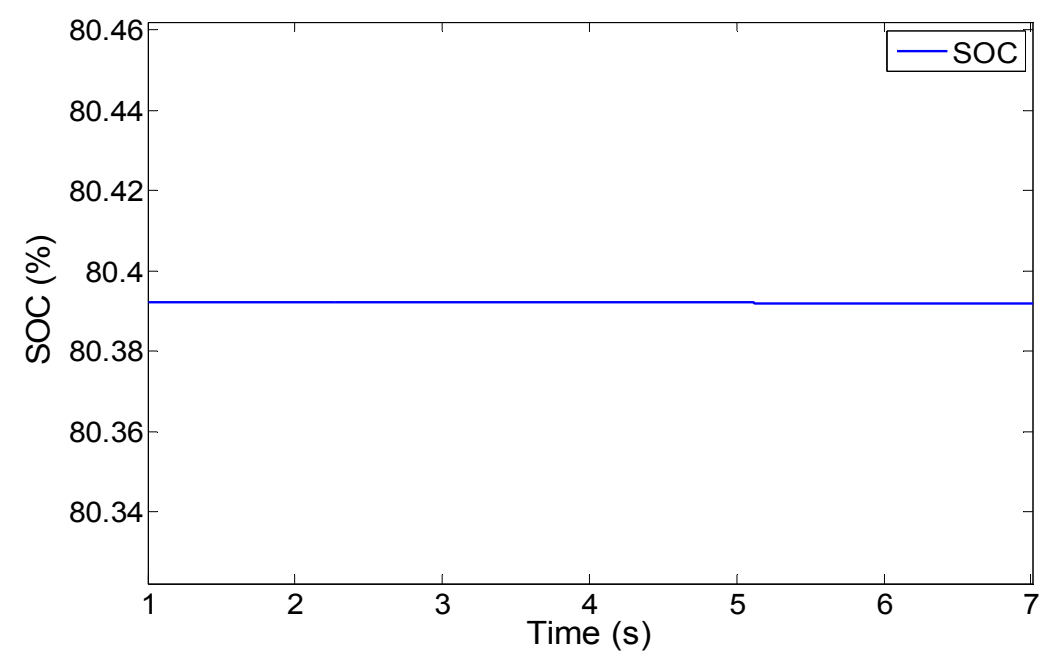

Figure 25. SOC level was constant in its maximum level under idle mode.

If the battery SOC level in the second case has room to do the charging action, the battery can absorb power, as mentioned in the power management scheme. Furthermore, another simulation was performed by setting the battery SOC to $34.64 \%$. The excess power in the microgrid could then transfer into the battery by the converter control to regulate the DC voltage. From Figures 26 and 27, one can notice that the DC voltage was properly regulated and that the SOC level was increased by its charging action.

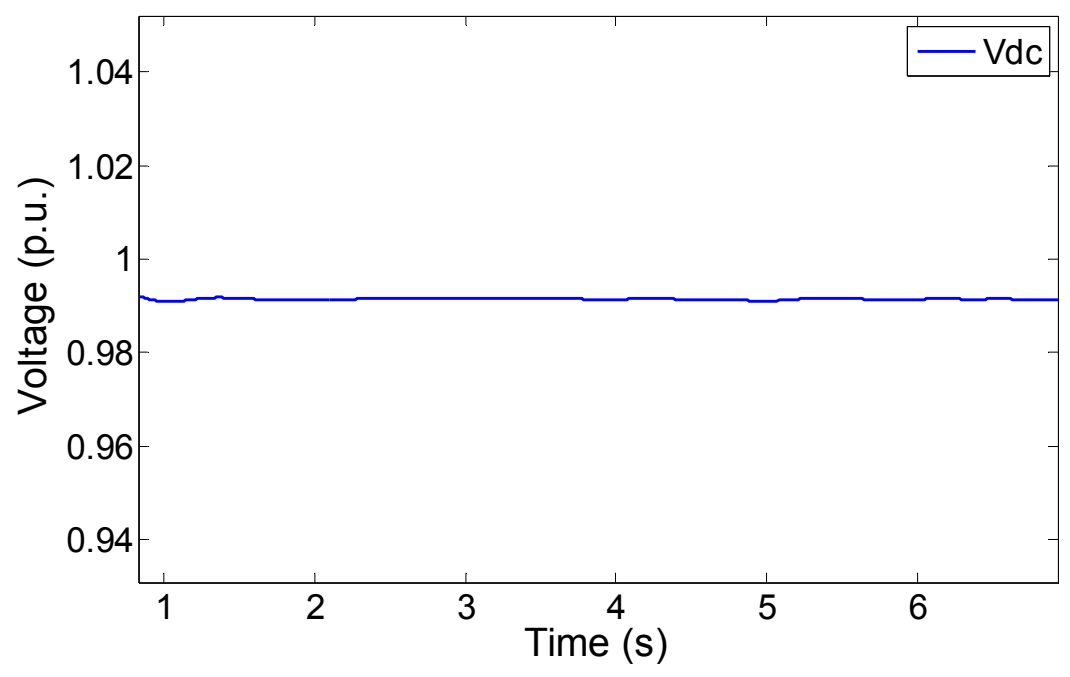

Figure 26. DC voltage in the second case, when $\Delta P$ was not limited.

Another case was studied with slightly modified system parameters from the first case, and the utility grid support was increased by around $10 \mathrm{~kW}$. At $t=5 \mathrm{~s}$, the system operation mode changed into the stand-alone hybrid microgrid. To restore the system frequency, a portion of the AC load was shed, and the amount was $75 \%$ of the power support from the utility grid before the mode change. Using the conventional droop control scheme, at the beginning, the frequency was able to increase, approaching the nominal value by the load shedding action, but around $0.2 \mathrm{~s}$ after the action, the frequency started decreasing and severely oscillated around $58.5 \mathrm{~Hz}$. To avoid the frequency instability, the proposed control strategy applied the action for limiting the IC injection. A $0.5-\mathrm{Hz}$ frequency deadband was used on the limitation scheme of DC voltage and the IC initial active power setting 
point; that is, the incremental power for DC voltage regulation and the IC initial set point was confined to (18) and (19). From Figure 28, one can notice that the system frequency was restored and settled down around $59.65 \mathrm{~Hz}$ when using the proposed scheme.

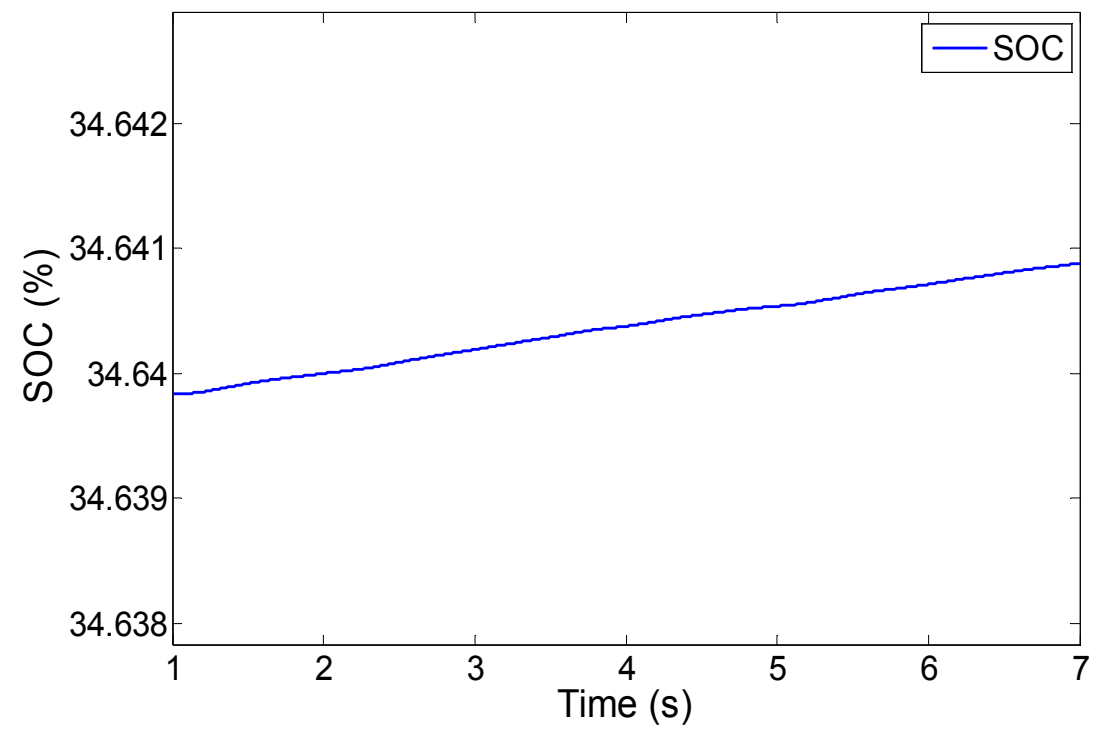

Figure 27. SOC level in the second case, when $\Delta P$ was not limited.

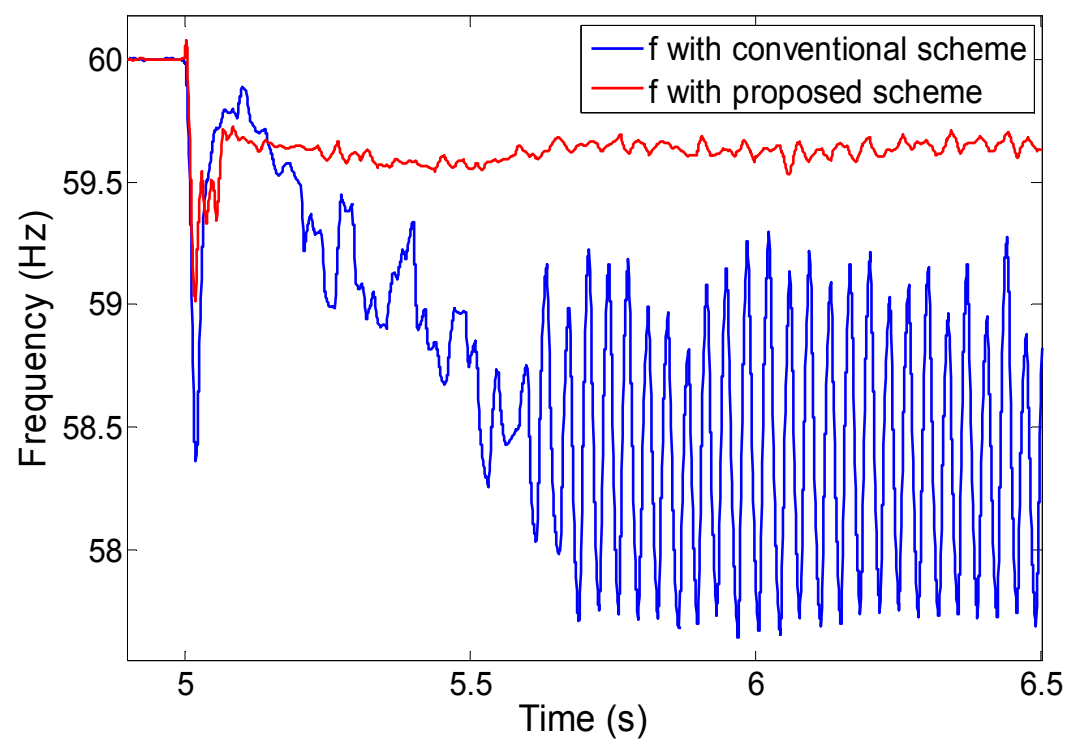

Figure 28. Comparison of the frequency responses using the conventional and the proposed droop control scheme.

\section{Conclusions}

The objective of the IC controller is to regulate the frequency of the AC subgrid and the bus voltage of the DC subgrid by the control of the active power injection via the IC. The change in the power injection is followed by the support of the BESS in the DC subgrid because of its DC bus voltage regulation. Thus, when the SOC of the BESS is exhausted or fully charged, the change in the active power injection needs to be managed along with the physical limits of the battery SOC. The proposed coordination control strategy can provide a smooth transition on power transfer through the IC of the 
microgrid in stand-alone mode, and from the simulation results, one can notice that the control strategy can manage the power transfer effectively, even when a load shedding is applied in weak conditions.

Acknowledgments: This work was supported by the Human Resources Development of the Korea Institute of Energy Technology Evaluation and Planning (KETEP) grant funded by the Ministry of Trade, Industry \& Energy of the Korea government (No. 20154030200720).

Author Contributions: Dwi R. Aryani surveyed the backgrounds of this research, designed the control strategies, and performed the simulations so as to show the benefits of the proposed method. Hwachang Song supervised and supported this study.

Conflicts of Interest: The authors declare no conflict of interest.

\section{Nomenclature}

$\lambda$

$\beta$

$\Delta f$

$\Delta P$

$\Delta Q$

$\Delta V_{d c}$

$\Delta V_{d c}^{\prime}$

$\rho$

$\tau$

$\tau_{a}$

$\omega_{d}$

$\omega_{d, r e f}$

$\omega_{w}$

$\omega_{w, r e f}$

A

$C_{1}, C_{2}$

$C_{p}$

$E_{m}$

$f_{m}$

$f_{\text {nom }}$

$f_{0, a c}$

$f_{\text {min, }, a c}$

$G_{m}$

$I_{b a t}$

$K_{a}$

$K_{b}$

$K_{i}$

$K_{p}$

$K_{p, a c}$

$K_{p, d c}$

$K_{q, a c}$

$K_{s}$

$k_{f}$

$P_{0, a c}$

$P_{0, d c}$

$P_{b a t}$

$P_{g}$ tip speed ratio

blade pitch angle

frequency deviation

active power injection generated by IC droop control

reactive power injection generated by IC droop control

DC voltage deviation

limited DC voltage deviation

air density

dead time

actuator time constant

diesel mechanical speed

reference speed of the diesel machine

mechanical speed of the wind turbine

reference speed of the machine

rotor swept area

battery capacitances

power coefficient

open circuit voltage of the battery

measured frequency

nominal frequency

nominal frequency of the AC microgrid

minimum allowable frequency in the AC microgrid

gain multiplier

battery current

diesel actuator gain

blade actuator integral gain

integral gain

proportional gain

f-P droop gain in the AC microgrid

$\mathrm{V}-\mathrm{P}$ droop gain in the $\mathrm{DC}$ microgrid

$\mathrm{Q}-\mathrm{V}$ droop gain in the $\mathrm{AC}$ microgrid

wind turbine droop gain

gain for the limiter of DC voltage or the IC active power set point

pre-specified active power output in the AC microgrid

pre-specified active power output in the DC microgrid

battery active power

power output of the wind turbine based on machine rating 
$P_{g, r e f} \quad$ power demand

$P_{I C, 0} \quad$ IC active power set point

$P_{I C, 0}^{\prime} \quad$ limited IC active power set point

$P_{I C}^{*} \quad$ IC active power reference

$P_{l, a c} \quad$ AC loads' active power

$P_{l, d c} \quad$ DC loads' active power

$P_{\max , a c} \quad$ maximum active power generated by droop control in the AC microgrid

$P_{\text {max }, d c} \quad$ maximum active power generated by droop control in the DC microgrid

$P_{\text {net }} \quad$ net active power

$P_{s, a c} \quad$ AC sources' active power

$P_{s, d c} \quad$ DC sources' active power

$P_{w} \quad$ wind turbine output power

$Q_{0, a c} \quad$ pre-specified reactive power output in the AC microgrid

$Q_{\text {cap }} \quad$ battery capacity

$Q_{I C}^{*} \quad$ IC reactive power reference

$Q_{\max , a c} \quad$ maximum reactive power generated by the droop control in the AC microgrid

$R_{0}, R_{1}, R_{2} \quad$ battery resistances

$R_{d} \quad$ diesel droop characteristics

$R_{p} \quad$ IC droop characteristic for active power transfer

$R_{q} \quad$ IC droop characteristic for reactive power transfer

SOC battery state of charge (SOC) level

$T_{m} \quad$ mechanical torque

$V_{0, a c} \quad$ base voltage of the AC microgrid

$V_{0, d c} \quad$ base voltage of the DC microgrid

$V_{a c} \quad$ measured AC voltage

$V_{a c, n o m} \quad$ nominal voltage of the AC microgrid

$V_{\text {bat }} \quad$ battery terminal voltage

$V_{d c, m} \quad$ measured DC bus voltage

$V_{d c, n o m} \quad$ nominal voltage of the DC microgrid

$V_{\text {min }, a c} \quad$ minimum allowable voltage in the AC microgrid

$V_{\min , d c} \quad$ minimum allowable voltage in the DC microgrid

$v_{w} \quad$ wind speed

$Z_{\text {tot }} \quad$ total battery impedance

\section{References}

1. Lasseter, R.H.; Paigi, P. Microgrid: A conceptual solution. In Proceedings of the 35th IEEE Power Electronics Specialists Conference, Aachen, Germany, 20-25 June 2004.

2. Singh, A.; Surjan, B.S. Microgrid: A review. Int. J. Res. Eng. Technol. 2014, 3, 185-198.

3. Sannino, A.; Postiglione, G.; Bollen, M.H.J. Feasibility of a DC network for commercial facilities. IEEE Trans. Ind. Appl. 2003, 39, 1499-1507. [CrossRef]

4. Hatziargyriou, N. Microgirds: Architectures and Control; IEEE Press: Baltimore, MD, USA, 2014.

5. Raju, E.S.N.P.; Trapti, J. Hybrid AC/DC micro grid: An overview. In Proceedings of the Fifth International Conference on Power and Energy Systems, Kathmandu, Nepal, 28-30 October 2013.

6. Liu, X.; Wang, P.; Loh, P.C. A hybrid AC/DC microgrid and its coordination control. IEEE Trans. Smart Grid 2011, 2, 278-286.

7. Sao, C.K.; Lehn, P.W. Control and power management of converter fed microgrids. IEEE Trans. Power Syst. 2008, 23, 1088-1098. [CrossRef]

8. Guerrero, J.M.; Vasquez, J.C.; Matas, J.; de Vicuña, L.G.; Castilla, M. Hierarchical control of droop-controlled AC and DC microgrids-A general approach toward standardization. IEEE Trans. Ind. Electron. 2011, 58, 158-172. [CrossRef] 
9. Lu, X.; Guerrero, J.M.; Sun, K.; Vasquez, J.C.; Teodorescu, R.; Huang, L. Hierarchical control of parallel AC-DC converter interfaces for hybrid microgrids. IEEE Trans. Smart Grid 2014, 5, 683-692. [CrossRef]

10. Eghtedarpour, N.; Farjah, E. Power control and management in a hybrid AC/DC microgrid. IEEE Trans. Smart Grid 2014, 5, 1494-1505. [CrossRef]

11. Loh, P.C.; Li, D.; Chai, Y.K.; Blaabjerg, F. Autonomous operation of hybrid microgrid with AC and DC subgrids. IEEE Trans. Power Electron. 2013, 28, 2214-2223. [CrossRef]

12. Loh, P.C.; Li, D.; Chai, Y.K.; Blaabjerg, F. Autonomous control of interlinking converter with energy storage in hybrid AC-DC microgrid. IEEE Trans. Ind. Appl. 2013, 49, 1374-1382. [CrossRef]

13. Dragicevic, T.; Guerrero, J.M.; Vasquez, J.C.; Skrlec, D. Supervisory control of an adaptive-droop regulated DC microgrid with battery management capability. IEEE Trans. Power Electron. 2014, 2, 695-706. [CrossRef]

14. Unamuno, E.; Barrena, J.A. Primary control operation modes in islanded hybrid AC/DC microgrids. In Proceedings of the IEEE EUROCON 2015-International Conference on Computer as a Tool (EUROCON), Salamanca, Spain, 8-11 September 2015; pp. 1-6.

15. Wang, X.; Yue, M.; Muljadi, E. Modeling and control system design for an integrated solar generation and energy storage system with a ride-through capability. In Proceedings of the IEEE Energy Conversion Congress and Exposition (ECCE), Raleigh, NC, USA, 15-20 September 2012.

(C) 2016 by the authors; licensee MDPI, Basel, Switzerland. This article is an open access article distributed under the terms and conditions of the Creative Commons Attribution (CC-BY) license (http://creativecommons.org/licenses/by/4.0/). 